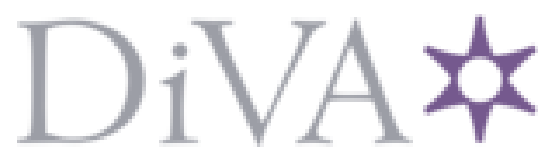

http://www.diva-portal.org

This is the published version of a paper published in Scandinavian Cardiovascular Journal.

Citation for the original published paper (version of record):

Karlström, P., Dahlström, U., Boman, K., Alehagen, U. (2015)

Responder to BNP-guided treatment in heart failure. The process of defining a responder Results from the Use of PeptideS in Tailoring hEart failure Project or UPSTEP study.

Scandinavian Cardiovascular Journal, 49(6): 316-324

http://dx.doi.org/10.3109/14017431.2015.1070961

Access to the published version may require subscription.

N.B. When citing this work, cite the original published paper.

Permanent link to this version:

http://urn.kb.se/resolve?urn=urn:nbn:se:umu:diva-117877 


\title{
Responder to BNP-guided treatment in heart failure. The process of defining a responder
}

\author{
Results from the Use of PeptideS in Tailoring hEart failure Project or UPSTEP study
}

\author{
PATRIC KARLSTRÖM${ }^{1}$, ULF DAHLSTRÖM ${ }^{2}$, KURT BOMAN ${ }^{3} \&$ URBAN ALEHAGEN $^{2}$ \\ ${ }^{1}$ Department of Medicine, Division of Cardiology, County Hospital Ryhov, fönköping, Sweden, ${ }^{2}$ Department of Cardiology \\ and Department of Medical and Health Sciences, Linköping University, Linköping, Sweden, ${ }^{3}$ Research unit Skellefteå \\ Department of Medicine, Institution of Public Health and Clinical Medicine, Umeå University Sweden
}

\begin{abstract}
Objectives. B-type natriuretic peptide (BNP) levels predict prognosis and outcome in heart failure (HF) patients. To evaluate the optimal cut-off level of BNP to predict death, need for hospitalization, and worsening HF, and also to determine the optimal time to apply the chosen cut-off value.

Design. In a sub-study from the Use of PeptideS in Tailoring hEart failure Project or UPSTEP study where tailoring treatment of HF by BNP level was evaluated, we assessed the change in percentage between levels of BNP at study start versus a specific week $(2,6,10,16,24,36$, or 48$)$ during the follow-up period.

Results. The optimum cut-off percentage levels were obtained using a Cox proportional regression analysis of death, hospitalization, and worsening HF. A decrease in BNP by less than $40 \%$ in week 16 compared with study start and/or a $\mathrm{BNP}>300 \mathrm{ng} / \mathrm{L}$ presented the highest hazard ratio (HR) for a non-responder to reach a combined endpoint (HR: 2.43; $95 \%$ confidence interval or CI: $1.61-3.65 ; p<0.00003)$.

This definition gave a $78 \%$ risk reduction of cardiovascular $(\mathrm{CV})$ mortality $(p>0.0005)$ and an $89 \%$ risk reduction of $\mathrm{HF}$ mortality $(p>0.004)$, and reduced risk of CV and HF hospitalization for the responders.

Conclusions. Patients with a decrease in BNP of more than $40 \%$ compared with that at study start and/or a BNP level below $300 \mathrm{ng} / \mathrm{L}$ at week 16 had a significantly reduced risk of CV and HF mortality and hospitalization.
\end{abstract}

Key words: BNP, heart failure, natriuretic peptides, responder, treatment

\section{Introduction}

Heart failure (HF) is a syndrome with high mortality and morbidity (1), reduced quality of life, and a concomitant increase in hospitalization (2). In the last decade there has been a decrease in mortality and morbidity due to improved pharmacological treatment (3). Apart from being a valuable tool in diagnosing $\mathrm{HF}$, measuring B-type natriuretic peptide (BNP) at hospital admission has been shown to be a significant predictor of in-hospital mortality for patients with acute decompensated HF (ADHF) (4). In these patients, a high hospital pre-discharge peptide concentration was a useful tool for risk stratification of re-admission and mortality $(5,6)$.
In a retrospective analysis of the SURVIVE study (Levosimendan versus dobutamine in long-term survival), Cohen-Solal et al. showed that patients with severe ADHF in whom BNP concentration reduced on treatment by at least $30 \%$ between baseline and day 5 had an improved survival rate (7). This was also found in the Val-HeFT, a chronic HF trial. (8). However, it is not known if these findings are applicable to HF patients in an outpatient setting.

Whether it is an advantage to use natriuretic peptides in guiding medical therapy is a matter of debate. In the literature, there are different studies addressing BNP-guided treatment, and all except two of these used different absolute natriuretic

Correspondence: Patric Karlström, Department of Medicine, Division of Cardiology, County Hospital Ryhov, Jönköping 55338 , Sweden. Tel: + 4636 321982. Fax: + 4636 322088. E-mail: patric.karlstrom@lj.se

(C) 2015 The Author(s). Published by Taylor \& Francis. This is an Open Access article distributed under the terms of the Creative Commons AttributionNonCommercial-NoDerivatives License (http://creativecommons.org/Licenses/by-nc-nd/4.0/), which permits non-commercial re-use, distribution, and reproduction in any medium, provided the original work is properly cited, and is not altered, transformed, or built upon in any way. 
peptide target levels and different treatment algorithms (9-17). None of the studies evaluated the optimal BNP/NT-proBNP level or when to apply the obtained level in relation to the treatment effect regarding mortality and morbidity.

In the UPSTEP study a significantly lower mortality and morbidity could be demonstrated in patients with chronic HF who were classified as responders compared with those classified as nonresponders (15). The pre-specified definition of a responder was a $30 \%$ decrease in BNP concentration in study week 48 compared with that in the study start. There is no consensus on when or how much reduction in BNP level is required to identify risk patients.

Aim

The aim of this study was to evaluate the optimal BNP level change as a result of HF treatment combined with an absolute BNP level value for predicting death, need for hospitalization, or worsening of HF, and also to determine the optimal time to apply the chosen level combination.

\section{Methods}

The UPSTEP study was an investigator-initiated Scandinavian multicenter study on patients with $\mathrm{HF}$ in the New York Heart Association (NYHA) class II-IV. It had a prospective, randomized, open, blinded evaluation (PROBE) design that was described earlier (15). The definition of HF used was symptoms/ signs of heart failure and an objective verification of impaired systolic function as seen on echocardiographic examination, as recommended by guidelines.

After an episode of worsening $\mathrm{HF}$ within the last month the patients were randomized into a BNPguided treatment group $(\mathrm{n}=147)$ and a control group (conventionally treated, $n=132$ ).

Worsening HF was defined as requiring hospitalization and/or intravenous diuretic treatment, metolazone, or increased daily dosages of diuretics and/or need of intravenous inotropic support. The patients had to have a verified left ventricular ejection fraction (LVEF) $<40 \%$, assessed within the last six months. The study was conducted in 19 hospitals in Sweden and Norway.

In the BNP-guided group, the following treatment algorithm was used to reduce elevated BNP levels to the goal $(<150 \mathrm{ng} / \mathrm{L}$ in patients $<75$ years and $<300 \mathrm{ng} / \mathrm{L}$ in patients $\geq 75$ years); increase angiotensin receptor inhibitor (ACEI)/angiotensin receptor blocker (ARB) to the maximum tolerated or to the target dose according to guidelines; increase beta-blocker (BB) to the maximum tolerated or to the target dose according to guidelines; add mineralocorticoid receptor antagonist (MRA) in a low dose (spironolactone, $25 \mathrm{mg}$ ); add ARB and increase it to the target dose according to guidelines; increase $\mathrm{ACEI} / \mathrm{ARB}$ up to twice the target dose; increase $\mathrm{BB}$ up to twice the target dose; and increase spironolactone up to a dose of $50 \mathrm{mg}$.

The primary outcome variable was a composite of death due to any cause, need for hospitalization, and worsening HF. Worsening HF was defined as a need to increase diuretics orally or intravenously but no need for hospitalization.

The present study is based on the clinical and blood sample data from the UPSTEP study.

\section{BNP analyses}

Blood samples for BNP analysis were collected in ethylenediaminetetraacetic acid or EDTA-coated vials and analyzed on-site by means of the fluorescence immunoassay technique (Triage, Biosite Inc., San Diego, CA, USA), as described in our previous publication on this study population (15). The technique of analysis has been previously described in detail $(18,19)$.

\section{Ethics}

The study protocol of UPSTEP was approved by the Regional Ethical Review Board in Linkoping, Sweden. Every patient signed an informed consent before entering the trial.

\section{Statistics}

All descriptive data are presented as percentages or as mean and standard deviations (SDs). Continuous variables were analyzed with the Student's unpaired two-sided $t$-test, whereas the chi-squared test was used for discrete variables. Event-free survival was evaluated with Kaplan-Meier analyses. The prognostic information was evaluated using the Cox proportional hazards regression analysis. In the multivariate setting the following covariates that are known to influence cardiovascular risk were included in the model; age $>75$ years, male gender, diabetes mellitus, NYHA functional classes III and IV, hypertension, ischemic heart disease, previous and present smoking, and estimated glomerular filtration rate (eGFR) $<60 \mathrm{ml} / \mathrm{min} / 1.73 \mathrm{~m}^{2}$.

To define a "responder" we divided the BNP value at a specific week with the BNP value at study start. The factor was then subtracted from 1 , and this 
was the percentage change for the patient in that week. If the patient's value was lower than the percentage value, the patient was defined as a "responder." We analyzed BNP values at weeks 6, 10, 16, 24, and 36.

We also added a lower limit for the BNP level ( $\leq 150 \mathrm{ng} / \mathrm{l}, \leq 200 \mathrm{ng} / 1, \leq 250 \mathrm{ng} / 1$, and $\leq 300$ ng/l). Patients below these values at follow-up were defined as responders. Groups with fewer than 2 5 patients were disregarded due to statistical insecurity.

If the patient had a missing value we used the last known value of BNP. To obtain the optimum cut-off percentage level of BNP we explored the hazard ratios (HRs) as obtained using a univariate Cox proportional regression analysis for the primary outcome variable from week 6 until week 36, and based on changes in BNP levels from a decrease of $5 \%$ to $60 \%$. In the analyses we compared the group above the cut-off percentage level of BNP to the group below the cut-off BNP level. Our primary outcome variable was a composite endpoint of both mortality and morbidity and we used time to first event analysis.

We applied a modified scoring system first presented by Taylor et al.; one point was added for every episode of worsening $\mathrm{HF}$, each hospitalization added two points, and death due to any cause added four points (20).

A $p$ value $<0.05$ was considered statistically significant. All calculations were performed on commercial statistical software packages (Statistica v10) (Statsoft Inc, Tulsa, OK, 74104 USA).

\section{Results}

\section{Defining a cut-off level in size and time}

The optimum cut-off level of BNP as evaluated through the univariate Cox proportional hazard regression analysis was based on the result that presented the highest $\mathrm{HR}$ for a non-responder by applying different levels of reduction of BNP level, as well as different times of evaluation. In Figure 1, we present the $\mathrm{HR}$ for different weeks, and with different cut-off levels of BNP from a decrease of $20-60 \%$. We also performed analyses including cutoff levels of BNP including 35, 40, 45, and 50\% at the specified weeks of follow-up with regard to the primary outcome variable.

In the next step, we analyzed the percentage of $\mathrm{BNP}$ reduction and added a lower limit for $\mathrm{BNP}$ value $(\leq 150 \mathrm{ng} / \mathrm{l}, \leq 200 \mathrm{ng} / \mathrm{l}, \leq 250 \mathrm{ng} / \mathrm{l}$, and $\leq 300$ ng/l). Finally, we combined a fixed BNP value with the percentage change in BNP in a specific week compared with BNP at study start.

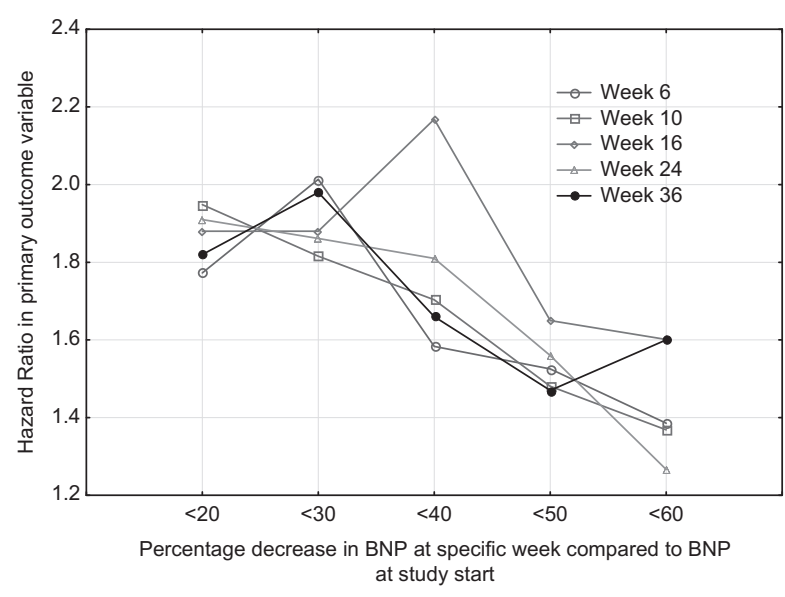

Figure 1. HR for primary outcome variables in different weeks, and percentage changes in BNP. HR from a univariate Cox proportional regression analysis obtained for death due to any cause, need for hospitalization, or worsening of $\mathrm{HF}$ as a reflection of percentage decrease in BNP at different weeks compared with BNP at study start.

The optimum cut-off level of BNP as evaluated through the univariate Cox proportional hazard regression analysis was based on the result that the highest $\mathrm{HR}$ for a non-responder was obtained using a $40 \%$ decrease or less in BNP level as the cut-off level in week 16 with combination of $\mathrm{BNP}<300 \mathrm{ng} / 1$ of our primary outcome variable (HR: $2.43 ; 95 \%$ confidence interval [CI]: 1.61-3.65; $p<0.00003)$. We chose $\mathrm{BNP}<300 \mathrm{ng} / 1$ for two reasons. Firstly, it gave the highest $\mathrm{HR}$ of the fixed $\mathrm{BNP}$ values, and secondly patients older than 75 years had BNP $300 \mathrm{ng} / \mathrm{l}$ as a goal in the treatment algorithm.

\section{Applying the obtained responder definition}

Baseline characteristics. By applying the definition of a responder described above to the study population we found that $84(60 \%)$ were responders and 56 (40\%) were non-responders. Baseline characteristics are shown in Table I. As can be seen, there was a difference in age between the groups. However, in a multivariate regression, age did not influence the independent variables.

We also evaluated a modified model, where all patients younger than 60 years of age were excluded. This had no influence on the regression results. Our results were consistent also when excluding all patients who died prior to week $16(n=6)$. A Cox proportional regression analysis gave a $\mathrm{HR}$ of 0.45 (95\% CI: $0.30-0.69, p<0.0002$ ) for the responders analyzed for the primary outcome variable. Thus, patients alive in week 16, who had a BNP level reduction of more than $40 \%$ and/or a $\mathrm{BNP}<300 \mathrm{ng} / \mathrm{l}$, were associated with a $55 \%$ lower risk of suffering a primary endpoint than non-responders. 
Table I. Baseline characteristics for responders versus non-responders in week 16 at a $40 \%$ decrease in BNP compared with those at study start or an absolute BNP value $<300 \mathrm{ng} / \mathrm{l}$.

\begin{tabular}{|c|c|c|c|}
\hline Characteristics & $\begin{array}{l}\text { Responders } \\
\quad n=84\end{array}$ & $\begin{array}{c}\text { Non-responders } \\
\quad n=56\end{array}$ & $p$ value \\
\hline Age years (SD) & $69.3( \pm 10.4)$ & $74.3( \pm 7.9)$ & 0.003 \\
\hline$<60$ years $/>80$ years & $16 / 13$ & $1 / 14$ & 0.04 \\
\hline$>75$ years $n(\%)$ & $29(35)$ & $29(52)$ & \\
\hline Gender male $n(\%)$ & $66(79)$ & $37(66)$ & 0.10 \\
\hline Hypertension $n(\%)$ & $37(44)$ & $33(59)$ & 0.08 \\
\hline Diabetes mellitus $n(\%)$ & $22(26)$ & $15(27)$ & 0.94 \\
\hline Coronary artery disease $\mathrm{n}(\%)$ & $44(52)$ & $33(59)$ & 0.45 \\
\hline \multicolumn{4}{|l|}{ Physical examination } \\
\hline Heart rate beats/min (SD) & $79( \pm 20)$ & $72( \pm 15)$ & 0.03 \\
\hline QRS duration ms (SD) & $125.7( \pm 35.2)$ & $127.9( \pm 40.2)$ & 0.73 \\
\hline Systolic blood pressure $\mathrm{mmHg}$ & $126( \pm 23)$ & $125( \pm 21)$ & 0.80 \\
\hline Diastolic blood pressure $\mathrm{mmHg}$ & $75( \pm 14)$ & $74( \pm 12)$ & 0.65 \\
\hline \multicolumn{4}{|l|}{ NYHA functional classes } \\
\hline II $n$ & 29 & 18 & 0.77 \\
\hline III $n$ & 43 & 29 & 0.94 \\
\hline IV n & 11 & 9 & 0.62 \\
\hline \multicolumn{4}{|l|}{ Medication } \\
\hline RAS $n(\%)$ & $84(100)$ & $55(99)$ & 0.22 \\
\hline $\mathrm{BB} n(\%)$ & $79(94)$ & $51(92)$ & 0.50 \\
\hline MRA $n(\%)$ & $48(57)$ & $29(52)$ & 0.53 \\
\hline Diuretics $n(\%)$ & $69(82)$ & $48(86)$ & 0.40 \\
\hline \multicolumn{4}{|l|}{ Echocardiography (LVEF) } \\
\hline$<30 \% n(\%)$ & $54(64)$ & $27(48)$ & 0.06 \\
\hline $30-40 \% n(\%)$ & $30(36)$ & $29(52)$ & 0.06 \\
\hline \multicolumn{4}{|l|}{ Laboratory results } \\
\hline BNP ng/l mean (SD) & $795( \pm 680)$ & $805( \pm 688)$ & 0.93 \\
\hline median & 583 & 634 & \\
\hline $\mathrm{Hb}$ g/l mean (SD) & $138( \pm 14.7)$ & $135( \pm 14.3)$ & 0.67 \\
\hline Creatinine $\mu \mathrm{mol} / 1$ mean $(\mathrm{SD})$ & $100( \pm 27.8)$ & $115( \pm 38.5)$ & 0.009 \\
\hline Potassium $\mathrm{mmol} / \mathrm{l}$ mean (SD) & $4.3( \pm 0.49)$ & $4.3( \pm 0.54)$ & 0.73 \\
\hline Sodium mmol/1 mean (SD) & $140( \pm 3.1)$ & $140( \pm 3.9)$ & 0.57 \\
\hline $\mathrm{BMI}$ mean $(\mathrm{SD})$ & $26.7( \pm 4.8)$ & $26.8( \pm 4.1)$ & 0.89 \\
\hline
\end{tabular}

BB, Beta blocker; BNP, Brain natriuretic peptide; BMI, Body Mass Index; Hb, Hemoglobulin; LVEF, Left Ventricular Ejection Fraction; MRA, mineralcorticoid receptor antagonist; ms, milliseconds; NYHA, New York Heart Association functional class; RAS, Renin Angiotensin System Blockage; SD, standard deviation.

As shown in Table II there were no differences in medication, blood pressure, heart rate, and s-potassium or BNP levels between responders and nonresponders at study start. However, in week 16 the responder group had a lower mean BNP value compared with the non-responders $(244 \mathrm{ng} / \mathrm{L}( \pm 210)$ vs. $784 \mathrm{ng} / \mathrm{L}( \pm 752) ; p<0.0001)$. As can be seen in Table II, changes in doses of ACEI, ARB, BB, and MRA could be seen when comparing doses at start, at week 16 , and at study end.

Finally, we looked at the mean BNP value for responders and non-responders at study start, at different weeks during the study, and at study end. As seen in Figure 2, the BNP values were significant lower in the responder group during the study compared with those in the non-responders, except at study start.

Primary outcome variables. Our primary outcome variable was a composite of death due to any cause, need for hospitalization, and worsening HF. Figure 3 illustrates the Kaplan-Meier analyses depicting timeto-first-event analyses for the primary outcome variable, and shows a significant event rate reduction for responders.

This could also be shown in the univariate Cox proportional regression analysis for primary outcome events, HR: 0.41 (95\% CI: 0.27-0.62, $p<0.00003)$.

The differences between responders and nonresponders were also maintained in the multivariate Cox regression analysis, HR: 0.45; (95\% CI: $0.30-$ $0.69 ; p=0.0002$ ) (Table III). When cardiovascular (CV) and HF mortality were analyzed, the same magnitude of reduction was found, as was also found for $\mathrm{CV}$ hospitalization, $\mathrm{HF}$ hospitalization, and worsening of $\mathrm{HF}$.

When applying the previously discussed composite score derived from the point system to our population, 
Table II. Characteristics in medication, physical examinations, and laboratory results at study start, week 16 , and study end for responders and non-responders.

\begin{tabular}{|c|c|c|c|c|c|c|c|}
\hline & Group & $\begin{array}{c}\text { Study start } \\
n=140\end{array}$ & $p$ value* & $\begin{array}{c}\text { Week } 16 \\
n=134\end{array}$ & $p$ value $*$ & $\begin{array}{c}\text { Study end } \\
n=109\end{array}$ & $p$ value ${ }^{*}$ \\
\hline SBP & Responder & $126( \pm 23)$ & 0.80 & $121( \pm 21)$ & 0.59 & $128( \pm 18)$ & 0.08 \\
\hline $\mathrm{mmHg}$ & Non-responder & $125( \pm 21)$ & & $119( \pm 20)$ & & $121( \pm 18)$ & \\
\hline DBP & Responder & $75( \pm 14)$ & 0.65 & $70( \pm 12)$ & 0.80 & $74( \pm 11)$ & 0.07 \\
\hline $\mathrm{mmHg}$ & Non-responder & $74( \pm 12)$ & & $71( \pm 11)$ & & $70( \pm 9)$ & \\
\hline HR & Responder & $79( \pm 20)$ & 0.03 & $66( \pm 13)$ & 0.48 & $68( \pm 13)$ & 0.67 \\
\hline bpm & Non-responder & $72( \pm 15)$ & & $68( \pm 13)$ & & $67( \pm 12)$ & \\
\hline ACEI & Responder & $16.9( \pm 6.6)$ & 0.70 & $20.3( \pm 5.9)$ & 0.38 & $22.0( \pm 8.6)$ & 0.39 \\
\hline $\mathrm{mg} /$ day & Non-responder & $17.5( \pm 6.8)$ & & $19.2( \pm 6.0)$ & & $20.2( \pm 8.7)$ & \\
\hline ARB & Responder & $15.8( \pm 9.0)$ & 0.70 & $21.7( \pm 9.7)$ & 0.25 & $25.9( \pm 8.9)$ & 0.12 \\
\hline $\mathrm{mg} /$ day & Non-responder & $17.0( \pm 11.9)$ & & $19.0( \pm 10.5)$ & & $22.1( \pm 10.2)$ & \\
\hline $\mathrm{BB}$ & Responder & $125.8( \pm 74.1)$ & 0.90 & $151.5( \pm 82.9)$ & 0.74 & $165.1( \pm 91.4)$ & 0.11 \\
\hline $\mathrm{mg} /$ day & onder & 127.5 & & 146.7 & & $135.4( \pm 82.7)$ & \\
\hline MRA & Responder & $26.6( \pm 8.8)$ & 0.66 & $25.2( \pm 9.9)$ & 0.78 & $27.7( \pm 16.0)$ & 0.39 \\
\hline $\mathrm{mg} /$ day & Non-responder & $27.6( \pm 11.3)$ & & $24.7( \pm 9.2)$ & & $31.2( \pm 13.1)$ & \\
\hline Creatinine & Responder & $100( \pm 28.0)$ & 0.01 & $118( \pm 41.4)$ & 0.58 & $151( \pm 38.3)$ & 0.43 \\
\hline$\mu \mathrm{mol} / 1$ & Non-responder & $115( \pm 38.5)$ & & $114( \pm 40.8)$ & & $122( \pm 46.8)$ & \\
\hline Potassium & Responder & $4.3( \pm 0.49)$ & 0.73 & $4.5( \pm 0.7)$ & 0.30 & $4.5( \pm 0.5)$ & 0.29 \\
\hline $\mathrm{mmol} / 1$ & Non-responder & $4.3( \pm 0.54)$ & & $4.4( \pm 0.5)$ & & $4.4( \pm 0.4)$ & \\
\hline BNP & Responder & $795( \pm 680)$ & 0.93 & $244( \pm 210)$ & $<0.0001$ & $290( \pm 337)$ & 0.0002 \\
\hline $\mathrm{ng} / 1$ & Non-responder & $805( \pm 688)$ & & $784( \pm 752)$ & & $641( \pm 604)$ & \\
\hline
\end{tabular}

ACEI, Angiotensin receptor inhibitor; ARB, Angiotensin receptor blocker; BB, Beta blocker; BNP, Brain Natriuretic Peptide; DBP, Diastolic blood pressure; HR, Heart rate; MRA, mineralcorticoid receptor antagonist; SBP, Systolic blood pressure; SD, standard deviation.

Data are shown as mean, \pm SD.

Doses are given for patients receiving the drug. ACEI are given in Enalapril equivalents $(20 \mathrm{mg}$ Enalapril $=10$ $\mathrm{mg}$ Ramipril $=20 \mathrm{mg}$ Lisinopril $=150 \mathrm{mg}$ Captopril. ARB are given in Candersartan equivalents (32 $\mathrm{mg}$ Candersartan $=320 \mathrm{mg}$ Valsartan $=100 \mathrm{mg}$ Losartan $=300 \mathrm{mg}$ Irbersartan). BB are given in Metoprolol equivalents $(200 \mathrm{mg}$ Metoprolol $=100 \mathrm{mg}$ Atenolol $=10 \mathrm{mg}$ Bisoprolol $=50 \mathrm{mg}$ Carvedilol. $\mathrm{MRA}$ are given in spironolactone equivalents ( $25 \mathrm{mg}$ Spironolactone $=25 \mathrm{mg}$ Eplerenone).

${ }^{*} p$-value is between groups at specified time.

the mean point score in the responder group was significantly lower in all parameters, and the total score was 3.03 for responders versus 6.45 for nonresponders, $p<0.0002$.

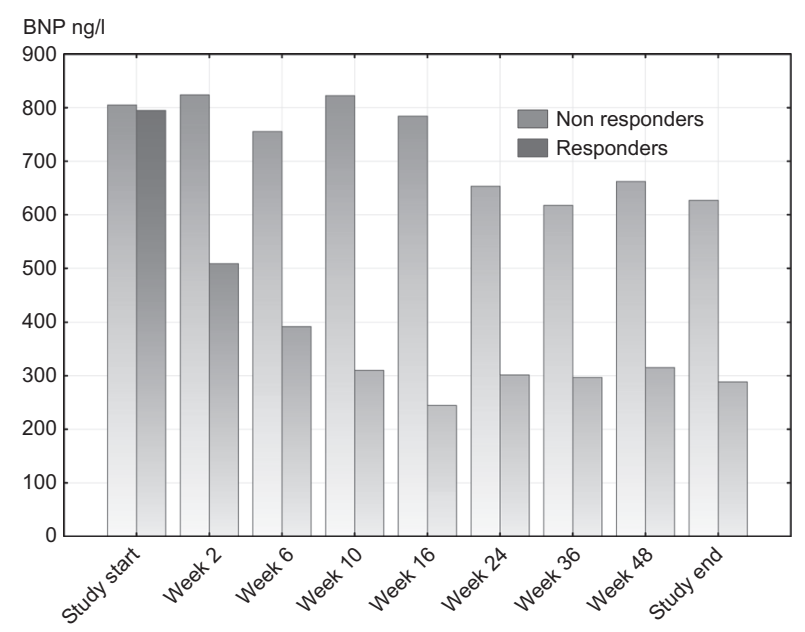

Figure 2. BNP value (mean) for responders and non-responders at study start, in different weeks during the study, and at study end. $P$ value; study start (0.93), week 2 (0.007), week 6 (0.0001), week $10(<0.0001)$, week $16(<0.0001)$, week $24(<0.0001)$, week 36 (0.0002), week 48 (0.0002), and study end (0.0002).
Secondary outcome variables. In the responder group, seven patients died from CV causes, compared with 21 for non-responders $(p<0.0001)$. The corresponding results for HF mortality were three patients in the responder group and 18 patients in the nonresponder group $(p<0.0001)$. Similar results were

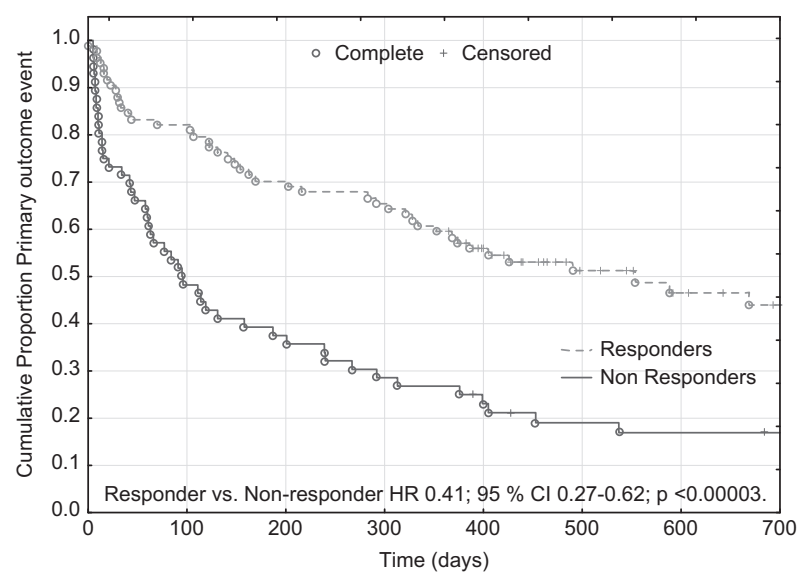

Figure 3. Kaplan-Meier curves showing primary outcome variable. Primary outcome variable (death from any cause, need for hospitalization, and worsening $\mathrm{HF}$ ) for responders versus nonresponders. 
Table III. Multivariate Cox regression analysis of primary and secondary outcome variables.

\begin{tabular}{|c|c|c|c|c|c|c|c|c|c|}
\hline & \multicolumn{3}{|c|}{ Primary Outcome event } & \multicolumn{3}{|c|}{ CV mortality } & \multicolumn{3}{|c|}{ HF mortality } \\
\hline & HR & $95 \% \mathrm{CI}$ & $p$ value & $\mathrm{HR}$ & $95 \% \mathrm{CI}$ & $p$ value & $\mathrm{HR}$ & $95 \% \mathrm{CI}$ & $p$ value \\
\hline Age $>75$ years & 1.06 & $0.67-1.69$ & 0.79 & 1.02 & $0.44-2.38$ & 0.96 & 1.13 & $0.43-3.00$ & 0.81 \\
\hline Male gender & 0.69 & $0.41-1.15$ & 0.15 & 0.86 & $0.32-2.32$ & 0.77 & 0.97 & $0.30-3.08$ & 0.96 \\
\hline Hypertension & 0.78 & $0.51-1.21$ & 0.27 & 0.58 & $0.24-1.40$ & 0.23 & 0.44 & $0.14-1.33$ & 0.14 \\
\hline IHD & 1.28 & $0.80-2.04$ & 0.31 & 1.32 & $0.56-3.11$ & 0.52 & 1.23 & $0.45-3.37$ & 0.69 \\
\hline Diabetes mellitus & 1.19 & $0.71-2.01$ & 0.50 & 1.62 & $0.62-4.23$ & 0.33 & 1.49 & $0.47-4.71$ & 0.49 \\
\hline $\mathrm{eGFR}<60 \mathrm{ml} / \mathrm{min} 1.73 \mathrm{~m}^{2}$ & 1.50 & $0.97-2.33$ & 0.07 & 2.18 & $0.90-5.31$ & 0.09 & 6.41 & $1.45-28.39$ & 0.01 \\
\hline NYHA III-IV & 1.99 & $1.24-3.21$ & 0.005 & 7.34 & $1.69-31.7$ & 0.008 & 11.2 & $1.45-85.77$ & 0.02 \\
\hline Smokers previous/present & 1.66 & $1.05-2.64$ & 0.03 & 0.95 & $0.41-2.18$ & 0.90 & 1.16 & $0.42-3.21$ & 0.77 \\
\hline Responder $<40 \% \& \mathrm{BNP}<300 \mathrm{ng} / 1$ & 0.48 & $0.31-0.74$ & 0.0008 & 0.25 & $0.10-0.60$ & 0.002 & 0.13 & $0.04-0.44$ & 0.001 \\
\hline
\end{tabular}

CI, confidence interval upper and lower; CV, Cardiovascular; eGFR, estimated glomerular filtration rate (MDRD formula); HF, Heart failure; HR, Hazard Ratio; IHD, Ischemic heart disease; NYHA, New York Heart Association functional class.

seen for CV hospitalization-73 events (responders) versus 107 events (non-responders), $p<0.003$ - and also HF hospitalization- 36 events versus 75 events, $p<0.003$. Regarding worsening $\mathrm{HF}$, there were 11 events (responders) versus 31 (non-responders), $p<0.002$.

The responder group spent fewer days in hospital for $\mathrm{CV}$ reasons: 4.4 days ( $\mathrm{SD} \pm 10.8$ ) versus 14.9 days $(\mathrm{SD} \pm 21.4)$ for non-responders, $p<0.0002$. The responder group also had fewer days in hospital due to HF: 2.3 days $(\mathrm{SD} \pm 9.2)$ versus, 9.4 days ( \pm SD 17.7), for non-responders $(p<0.002)$. There were no significant differences between the groups regarding non-CV hospitalization.

The total number of serious adverse events (SAEs) for responders was 113 events in 44 patients, and for non-responders it was 150 events in 48 patients. For worsening of $\mathrm{HF}$, classified as an $\mathrm{AE}$, there were 11 events in 9 responders and 31 AEs in 17 non-responders.

\section{Percentage model in comparison to the absolute reduction model}

In the literature, the most used model for defining a responder is one that involves use of an absolute cutoff level. Gaggin et al. defined a responder as a patient who has achieved a NT-proBNP value of $\leq 1000 \mathrm{pg} /$ $\mathrm{ml}$. We converted our BNP values into estimated NTproBNP values with a formula previously described by Sykes et al. $(\mathrm{BNP} \times 4.94+71.7-221.2$ (if female) $=$ NT-proBNP in ng/l) (21). By applying this definition to our population we got $46(33 \%)$ responders and $94(67 \%)$ non-responders. The obtained mean value of NT-proBNP from this transformation was $607 \mathrm{ng} / \mathrm{l}(\mathrm{SD} \pm 272)$ in the responder group versus $3568 \mathrm{ng} / 1$ (SD \pm 3815$), p<0.0001$ in the non-responder group. As we wanted to evaluate the "percentage model" used in the present model in comparison with the "absolute reduction model"here represented by Januzzi and Gaggin $(16,17)$-we applied the two models in a multivariate setting, thus letting the two models compete with each other and with other well-known clinical variables, during different weeks of evaluation, and using different relative levels of BNP reduction (Table IV). The results show that the "percentage model" gives independent and significant prognostic information even in competition with an "absolute reduction model."

\section{Discussion}

In clinical practice, it is difficult to evaluate the HF patient using standard care instruments. Clinical judgment and signs correlate poorly with tests of cardiac function (22) but serial measurements with BNP may help physicians with their clinical decisions regarding HF treatment.

In spite of a multitude of publications on the use of BNP as a biomarker for HF, until now only limited efforts have been made to define the most efficient cut-off values of BNP and when to measure BNP level in order to characterize a "responder." In the present study, the process of obtaining a definition of the "responder" is presented in terms of time and decrease in BNP level, in combination with an absolute BNP value, and to apply the acquired definition to the present study population.

The use of Cox proportional hazard regression analyses to obtain the measure of risk for a patient in reaching an endpoint is one way to analyze the effect of different cut-off values of the BNP concentration. The advantage of the method is that it implements when a specific endpoint occurs during the follow-up time as a way to give statistical weight to the specific endpoint in the evaluation. The disadvantage is that the strata analyzed may be narrow, which is why the uncertainty of the obtained results 
Table IV. Comparison between percentage model with a BNP cut point of $300 \mathrm{ng} / \mathrm{l}$, against an absolute model with definitions used by Januzzi and Gaggin, with a NT-proBNP cut point of $1000 \mathrm{pg} / \mathrm{ml}$ applied in a multivariate Cox proportional regressions model.

\begin{tabular}{|c|c|c|c|c|c|c|}
\hline \multirow{2}{*}{$\begin{array}{l}\text { Time and } \% \text { decrease and } \\
\text { BNP cut point } 300 \mathrm{ng} / 1\end{array}$} & \multicolumn{3}{|c|}{ Percentage model } & \multicolumn{3}{|c|}{ Absolute model } \\
\hline & Hazard ratio & $95 \% \mathrm{CI}$ & $p$ value & Hazard ratio & $95 \% \mathrm{CI}$ & $p$ value \\
\hline Week 6, 30\% & 1.67 & $1.02-2.73$ & 0.04 & 1.16 & $0.63-2.12$ & 0.64 \\
\hline Week 6, 40\% & 1.60 & $0.97-2.65$ & 0.07 & 1.12 & $0.59-2.11$ & 0.73 \\
\hline Week 6, 50\% & 1.47 & $0.86-2.51$ & 0.16 & 1.13 & $0.58-2.20$ & 0.71 \\
\hline Week 10, 30\% & 1.85 & $1.14-3.00$ & 0.01 & 0.80 & $0.43-1.50$ & 0.49 \\
\hline Week 10, 40\% & 2.13 & $1.28-3.55$ & 0.004 & 0.72 & $0.38-1.37$ & 0.31 \\
\hline Week 10, 50\% & 1.71 & $0.99-2.97$ & 0.06 & 0.78 & $0.40-1.52$ & 0.47 \\
\hline Week 16, 30\% & 2.08 & $1.27-3.42$ & 0.004 & 0.99 & $0.55-1.78$ & 0.96 \\
\hline Week 16, 40\% & 2.26 & $1.35-3.75$ & 0.002 & 0.92 & $0.50-1.69$ & 0.79 \\
\hline Week 16, 50\% & 1.74 & $1.01-2.99$ & 0.005 & 1.03 & $0.54-1.94$ & 0.94 \\
\hline Week 24, 30\% & 1.53 & $0.94-2.48$ & 0.09 & 1.38 & $0.75-2.56$ & 0.30 \\
\hline Week 24, 40\% & 1.30 & $0.80-2.11$ & 0.30 & 1.52 & $0.82-2.80$ & 0.18 \\
\hline Week $24,50 \%$ & 1.39 & $0.85-2.29$ & 0.19 & 1.45 & $0.78-2.70$ & 0.24 \\
\hline Week 36, 30\% & 1.63 & $1.22-4.11$ & 0.02 & 0.70 & $0.38-1.32$ & 0.27 \\
\hline Week 36, 40\% & 1.62 & $1.07-3.88$ & 0.02 & 0.64 & $0.33-1.26$ & 0.20 \\
\hline Week 36, 50\% & 1.56 & $0.87-2.34$ & 0.27 & 0.66 & $0.34-1.31$ & 0.23 \\
\hline
\end{tabular}

In the multivariate model, adjustments have been made for age $>75$ years, male gender, hypertension, ischemic heart disease, diabetes mellitus, eGFR $<60 \mathrm{ml} / \mathrm{min}$, NYHA class III or IV.

Comparison between week and percentage change included with an absolute BNP at $300 \mathrm{ng} / \mathrm{l}$ and an absolute cut point of NT-proBNP at $1000 \mathrm{ng} / \mathrm{l}$ suggested by Januzzi and Gaggin.

is high when applied to a relatively small sample size. We used a compromise regarding the size of the strata analyzed, taking into consideration the sample size, and using strata that were as wide as possible to generate a study hypothesis.

Different percentage cut-off values and different absolute BNP levels were used in this study. As changes in percentage may be overrated in cases of low baseline levels, whereas absolute values may be overrated in cases of high levels, we finally combined a fixed BNP value with the percentage change in $\mathrm{BNP}$ in a specific week compared with BNP at study start. In a multivariate Cox regression proportional hazard regression analysis including the clinical variables described above, the "percentage model" of BNP as described above was compared with an "absolute reduction" model as described by Januzzi et al. and Gaggin et al. $(16,17)$. The two models were included in the multivariate analysis at the same time in order to evaluate the result based on the competition between the models. From the result it could be seen that the presented "percentage model" gave better prognostic information compared with the "absolute model" in our study population.

Using the concept of applying a relative change of natriuretic peptides when establishing a responder is not new in the literature. In an interesting study, Neuhold et al. showed that the relative change in BNP levels did not add any prognostic information compared with an absolute level measured at a threemonth follow-up after an event of HF hospitalization (23). However, important differences between the
Neuhold study and the present study could be noted; in the Neuhold study the primary endpoint was allcause mortality, whereas in the present study the primary endpoint was a composite one, also including hospitalization and worsening HF. Neuhold also made just one measurement of the BNP level after three months, whereas in the present study the BNP levels were evaluated after $6,10,16,24$, and 36 weeks. We believe that these differences may explain the different results.

However, most of the reports on biomarkerguided therapy in patients with HF have used an absolute cut-off value and not a relative change in biomarker concentration.

As seen in Figure 1, the second highest $\mathrm{HR}$ for non-responders is at week 6 , at $30 \%$. This definition gives a HR of $0.50(95 \%$ CI: $0.33-0.75, p<0.001)$ for responders. With this definition we would have 73 non-responders and 67 responders. This is a small but important difference compared with the definition we choose with a HR of 0.41 (95\% CI: $0.27-0.62, p<0.00003)$, thus indicating that a $40 \%$ reduction at week 16 could be the most useful cut-off point in an HF population.

The mechanisms behind why certain patients will respond with a reduction in the biomarker, whereas others will not, are not addressed in this report.

Those who are shown to be non-responders should be regarded primarily as high-risk patients, and should be cared for as is already done with other cardiovascular high-risk patients. However, it is important to exclude other reasons for non-response to treatment, 
such as decreased compliance to medication, lifestyle influences, and need for device therapy.

The responder concept, we propose, gives new information on outpatients that supplements earlier findings. Therefore, we suggest that a $40 \%$ decrease in BNP value at week 16 compared with the baseline $\mathrm{BNP}$ value or an absolute value $<300 \mathrm{ng} / \mathrm{l}$ at week 16 after an episode of worsening HF is at least as effective as an absolute reduction level of the biomarker, as previously recommended in the literature.

\section{Study limitations}

The limited size of the evaluated population was one major limitation to exploring the different strata of BNP level. Another limitation was the fact that this was an explorative sub-group analysis that was not pre-specified. Thirdly, due to the small groups in each evaluation, the CIs regarding the HR were wide, hence the results need to be interpreted with caution.

Finally, the restricted age span of the study population was a limitation, making extrapolations of the results into other age groups difficult. However, as most patients with HF in the community are elderly, we argue that this study population was representative of actual HF patients in the community.

\section{Conclusion}

In this hypothesis-generating, explorative analysis of the UPSTEP study population, a novel concept of defining a responder to HF treatment based on a relative reduction of the BNP level combined with an absolute level of BNP is presented.

It could be demonstrated that using HR evaluation, a $40 \%$ decrease in BNP concentration at week 16 compared with that at study start and/or a BNP less than $300 \mathrm{ng} / \mathrm{L}$ obtained at week 16 best predicted long-term outcomes in $\mathrm{CV}$ and $\mathrm{HF}$ mortality and morbidity.

The obtained definition was also compared with one of the published models using an absolute cut-off level, and it could be demonstrated that a "percentage model" was at least not inferior to an absolute model.

\section{Acknowledgements}

We thank our patients, and the investigators and their staff, who made the UPSTEP study possible.

\section{Funding}

The Swedish Heart-lung foundation. The Regional Research Foundation in south-eastern Sweden and in northern Sweden funded the study. Biosite international and Infiniti Medical AB gave an unrestricted grant and provided the BNP analyzing equipment.

Declaration of interest: One of the authors (Ulf Dahlstrom) has served as a lecturer for Biosite. No conflicts of interest for the other authors have been reported.

\section{References}

1. McMurray JJ, Adamopoulos S, Anker SD, Auricchio A, Bohm M, Dickstein K, et al. ESC guidelines for the diagnosis and treatment of acute and chronic heart failure 2012: The Task Force for the Diagnosis and Treatment of Acute and Chronic Heart Failure 2012 of the European Society of Cardiology. Developed in collaboration with the Heart Failure Association (HFA) of the ESC. Eur J Heart Fail. 2012; 14:803-69.

2. Krumholz HM, Merrill AR, Schone EM, Schreiner GC, Chen J, Bradley EH, et al. Patterns of hospital performance in acute myocardial infarction and heart failure 30-day mortality and readmission. Circ Cardiovasc Qual Outcomes. 2009;2:407-13.

3. Schaufelberger $M$, Swedberg $\mathrm{K}$, Koster $\mathrm{M}$, Rosen $\mathrm{M}$, Rosengren A. Decreasing one-year mortality and hospitalization rates for heart failure in Sweden; Data from the Swedish Hospital Discharge Registry 1988 to 2000. Eur Heart J. 2004;25:300-7.

4. Fonarow GC, Peacock WF, Phillips CO, Givertz MM, Lopatin M, Committee ASA, et al. Admission B-type natriuretic peptide levels and in-hospital mortality in acute decompensated heart failure. J Am Coll Cardiol. 2007;49: 1943-50.

5. Bettencourt P, Azevedo A, Pimenta J, Frioes F, Ferreira S, Ferreira A. N-terminal-pro-brain natriuretic peptide predicts outcome after hospital discharge in heart failure patients. Circulation. 2004;110:2168-74.

6. Logeart D, Thabut G, Jourdain P, Chavelas C, Beyne P, Beauvais F, et al. Predischarge B-type natriuretic peptide assay for identifying patients at high risk of re-admission after decompensated heart failure. J Am Coll Cardiol. 2004; 43:635-41.

7. Cohen-Solal A, Logeart D, Huang B, Cai D, Nieminen MS, Mebazaa A. Lowered B-type natriuretic peptide in response to levosimendan or dobutamine treatment is associated with improved survival in patients with severe acutely decompensated heart failure. J Am Coll Cardiol. 2009;53:2343-8.

8. Anand IS, Fisher LD, Chiang YT, Latini R, Masson S, Maggioni AP, et al. Changes in brain natriuretic peptide and norepinephrine over time and mortality and morbidity in the Valsartan Heart Failure Trial (Val-HeFT). Circulation. 2003;107:1278-83.

9. Troughton RW, Frampton CM, Yandle TG, Espiner EA, Nicholls MG, Richards AM. Treatment of heart failure guided by plasma aminoterminal brain natriuretic peptide (N-BNP) concentrations. Lancet. 2000;355:1126-30.

10. Pfisterer $M$, Buser P, Rickli H, Gutmann M, Erne P, Rickenbacher $\mathrm{P}$, et al. BNP-guided vs symptom-guided heart failure therapy: the Trial of Intensified vs Standard Medical Therapy in Elderly Patients With Congestive Heart Failure (TIME-CHF) randomized trial. JAMA. 2009;301: 383-92. 


\section{P. Karlström et al.}

11. Lainchbury JG, Troughton RW, Strangman KM, Frampton CM, Pilbrow A, Yandle TG, et al. N-terminal proB-type natriuretic peptide-guided treatment for chronic heart failure: results from the BATTLESCARRED (NT-proBNPAssisted Treatment To Lessen Serial Cardiac Readmissions and Death) trial. J Am Coll Cardiol. 2009;55:53-60.

12. Eurlings LW, van Pol PE, Kok WE, van Wijk $S$, Lodewijks-van der Bolt C, Balk AH, et al. Management of chronic heart failure guided by individual $\mathrm{N}$-terminal pro-Btype natriuretic peptide targets: results of the PRIMA (Can PRo-brain-natriuretic peptide guided therapy of chronic heart failure IMprove heart fAilure morbidity and mortality?) study. J Am Coll Cardiol. 2010;56:2090-100.

13. Persson H, Erntell H, Eriksson B, Johansson G, Swedberg K, Dahlstrom U. Improved pharmacological therapy of chronic heart failure in primary care: a randomized Study of NTproBNP Guided Management of Heart Failure-SIGNAL-HF (Swedish Intervention study-Guidelines and NT-proBNP AnaLysis in Heart Failure). Eur J Heart Fail. 2010;12:1300-8.

14. Shah MR, Califf RM, Nohria A, Bhapkar M, Bowers M, Mancini DM, et al. The STARBRITE Trial: A Randomized, Pilot Study of B-Type Natriuretic Peptide-Guided Therapy in Patients With Advanced Heart Failure. J Card Fail. 2011;17:613-21.

15. Karlstrom P, Alehagen U, Boman K, Dahlstrom U, UPSTEPstudy group. Brain natriuretic peptide-guided treatment does not improve morbidity and mortality in extensively treated patients with chronic heart failure: responders to treatment have a significantly better outcome. Eur J Heart Fail. 2011; 13:1096-103.

16. Januzzi JL, Jr., Rehman SU, Mohammed AA, Bhardwaj A, Barajas L, Barajas J, et al. Use of amino-terminal pro-B-type natriuretic Peptide to guide outpatient therapy of patients with chronic left ventricular systolic dysfunction. J Am Coll Cardiol. 2011;58:1881-9.

17. Gaggin HK, Mohammed AA, Bhardwaj A, Rehman SU, Gregory SA, Weiner RB, et al. Heart failure outcomes and benefits of NT-proBNP-guided management in the elderly: results from the prospective, randomized ProBNP outpatient tailored chronic heart failure therapy (PROTECT) study. J Card Fail. 2012;18:626-34.

18. Vogeser M, Jacob K. B-type natriuretic peptide (BNP) validation of an immediate response assay. Clin Lab. 2001; 47:29-33.

19. Morrison LK, Harrison A, Krishnaswamy P, Kazanegra R, Clopton P, Maisel A. Utility of a rapid B-natriuretic peptide assay in differentiating congestive heart failure from lung disease in patients presenting with dyspnea. J Am Coll Cardiol. 2002;39:202-9.

20. Taylor AL, Ziesche S, Yancy C, Carson P, D’Agostino R Jr., Ferdinand $\mathrm{K}$, et al. Combination of isosorbide dinitrate and hydralazine in blacks with heart failure. N Engl J Med. 2004;351:2049-57.

21. Sykes E, Karcher RE, Eisenstadt J, Tushman DA, Balasubramaniam M, Gusway J, et al. Analytical relationships among Biosite, Bayer, and Roche methods for BNP and NT-proBNP. Am J Clin Pathol. 2005;123:584-90.

22. Stevenson LW, Perloff JK. The limited reliability of physical signs for estimating hemodynamics in chronic heart failure. JAMA. 1989;261:884-8.

23. Neuhold S, Huelsmann M, Strunk G, Struck J, Adlbrecht C, Gouya G, et al. Prognostic value of emerging neurohormones in chronic heart failure during optimization of heart failurespecific therapy. Clin Chem. 2010;56:121-6. 